\title{
Memories of my youth
}

\section{IGOR NIKOLAEVICH KOVALENKO}

Presidium of the National Academy of Sciences of Ukraine

Received May 5, 1995

When Vladimir Semenovich initially became one of my University lecturers, he was not yet a full Professor or Doctor of Mathematics. In the first half of the fifties he obtained very interesting results about random Boolean-valued walks, which is a hard combinatorial subject, working in collaboration with our teacher B.V. Gnedenko. But his first results regarding maximal deviations of random walks, which can be interpreted as both combinatorial and in terms of difference parabolic schemes, naturally needed further refinement, i.e. the construction of more precise asymptotics in a small parameter scheme. V.S. Korolyuk's initial approach consisted in a direct decomposition in a small parameter scheme. This approach did not give the desired result, because of the complexity of the nature of this problem. Therefore V.S. Korolyuk undertook the challenging task of untangling asymptotics. Progress was not smooth. He once said, 'I have to discover the true nature of things, I must see how asymptotics are structured.' This led to the application of the method of sequentially exhausting, originated by Vishik and Lusternik (in their work only on differential equations) and later to the development (together with A.F. Turbin) of the theory of perturbations of Markov operators on a spectrum. But we, the students of Kiev Taras Shevchenko University, first got acquainted with V.S. Korolyuk as a teacher of computer programming. He was a pioneer of computing techniques, and the author of address programming (together with E.L. Yushchenko and B.V. Gnedenko). He was so fascinated with this subject that he did not care whether his students understood his lectures. Words flew like bullets from a machine gun, and the chalk from the blackboard crumbled into dust; usually it was difficult to follow his lectures. But when he supervised the individual term papers and diploma projects he was very patient. Usually, in a laconic way he explained the method of the solution to the problem. A thinking student received almost all of what was necessary to solve their problem, but was left with a lot to think about. Stormy, 
hectic and frantic scenes near the blackboard can always be recalled, when Vladimir Semenovich was outraged with his students who did not understand things that he thought were obvious.

Many interesting scientists worked at the Department of Probability Theory at Kiev Taras Shevchenko University: B.V. Gnedenko (Head of the Department for many years), I.I. Gikhman, V.S. Korolyuk, V.S. Michalevich (but not for a long time), L.A. Kaluzhnin, M.I. Yadrenko and others. Those who seriously developed enthusiasm for cybernetics grouped around Lev Arkadievich Kaluzhnin - a world famous and very versatile scientist. Vladimir Semenovich had original ideas and opinions about algorithms, electronic computing machines and methods of computation.

"Cybernetic friends" with L.A. Kaluzhnin at the head usually walked through forests and over hills having scientific discussions. Young science students were gladly welcomed to this environment. Victor Michailovich Glushkov, as I remember, did not participate in these walks, but scientific news and information were shared with him. Victor Michailovich evaluated the contribution of V.S. Korolyuk highly.

V.S. Korolyuk played a leading role in the creation of the Computing Centre of the Academy of Sciences which was reborn as the giant Institute of Cybernetics. Vladimir Semenovich provided assistance and influenced the development of computer programming, computing methods, mathematical models of real phenomena right up to radar-location. It seems that the development of the theory of Ukrainian cybernetics has not been truthfully described yet (in the Soviet Union history was not always recorded truthfully in detail).

In 1957, B.V. Gnedenko was Director of The Institute of Mathematics of The Ukrainian Academy of Sciences and Head of the Department of Probability Theory there, and at the same time Head of the Department of Probability Theory of Taras Shevchenko University. His deputies were V.S. Korolyuk at the Institute and I.I. Gikhman at the University. In 1961, after the departure of Boris Vladimirovich Gnedenko to Moscow they inherited these positions. Getting ready for leaving for Moscow B.V. Gnedenko said, 'I must entrust the Department to Korolyuk'.

I worked at this Department till 1962 when I moved to Moscow, not to work with B.V. Gnedenko at Moscow Lomonosov University, but to a defence organization, where all the employees were promised flats.

Boris Vladimirovich attended his Department once a week. On this day, which was obligatory for attendance, the workshop of the Department took place, and expert consultations for the postgraduates were given. Vladimir Semenovich Korolyuk, although he was not formally my supervisor helped me a lot. Many other postgraduates also felt his help greatly. Because of the initiative of B.V. Gnedenko, we studied in particular, queueing systems with time restrictions (literal English 
meaning is "systems with impatient customers"). This problem was set forth for postgraduates S.M. Brody and M.G. Farinich, who were one year ahead of me in their postgraduate studies. Brody solved two problems: service with bounded waiting time and service with bounded stay of a "customer" in a system in a $M / G / 1$ scheme. As a first year postgraduate, I was not given any specific problem by my supervisor B.V. Gnedenko, and so I tried my abilities in different problems, selecting the more interesting ones. I took some problems from V.S. Michalevich undergoing on the postgraduate training by A.N. Kolmogorov. V.S. Korolyuk observed me rushing about without any definite direction and advised,'You should take problems with restrictions and invent the process which will unite all these problems'. He said nothing more. But this was sufficient for me, and in the same evening I found such a process. This incident characterizes the style of V.S. Korolyuk.

Problems associated with random walks led to the problem of the factorization of the kernel of an integral convolution equation. The question of the probabilistic interpretation of the factorization components arose in relation to this. This problem was given to me, and I obtained such an interpretation. The result of my work was published, and was even taken note of at a USSR Conference chaired by A.N. Kolmogorov. At that time D.V. Gusak, a postgraduate student of V.S. Korolyuk, started to study this topic seriously.

Another fact was that Vladimir Semenovich advised A.A. Borovkov to arm himself with the saddle-point method. And, being an analyst with great determination, A.A. Borovkov obtained by means of this method many important results associated with random walks. Vladimir Semenovich devoted a lot of his attention to queueing theory, or in the literal translation from Russian, "theory of mass customer service". In truth, he preferred to change the words "mass customer" and to say "theory of service systems". Indeed, this term is more precise. I remember, he advised me to study the famous article by Sir David Kendall, introducing into science the new notion "imbedded Markov processes". Possibly, Vladimir Semenovich was the first who realized in the middle of the fifties the importance of semi-Markov random processes, both in queueing and in the reliability theory of systems. He devoted great attention to all kinds (every reasonable possibility) of interpretations of semiMarkov processes and their functionals. V.S. Korolyuk was a teacher of the talented mathematician A.F. Turbin who perceived many of his ideas.

Kiev's mathematical school traditionally investigated small parameter methods and applied them whenever it was possible. The scientific school of nonlinear oscillations was created by N.N. Bogoliubov and Yu.A. Mitropolskii, and has obtained world fame. Vladimir Semenovich was an initiator of the investigations of asymptotic merging of phase states of semi-Markov random processes in a small parameter scheme. One day at the Institute of Mathematics a humorous wall newspaper was 
published. One of the caricatures was the following. Three men were carrying an enormous block with the inscription ' $\varepsilon$ ': two were ahead (these were local Professors) and only Vladimir Korolyuk with his legs giving way was behind. The caption to this caricature was: "What a heavy parameter! The load is hard although its volume is very small. But with the efforts of the two Professors it seems to be finished off".

Vladimir Korolyuk took hold of the hardest asymptotic problems. The formulas that came out were very complicated. It was easy to make a mistake. He often said, 'If a resultant expression is simple then I will not make a mistake. This is my criterion'.

V.S. Korolyuk knows how to support, to hearten, and sometimes to drive a young scientist. I remember that B.V. Gnedenko was irreconcilable with someone's failure to attend his workshop and even to arrive on time. At that time I was married, and my older daughter was born. As all postgraduates, I did not lose a chance to earn some money on the side in addition to my scholarship (68 rubles per month). There was a woman teacher in one of the Universities who had maternity leave, and I took her practical course upon myself. (This activity was called "whimpering". It was said,'Here he comes to whimper'. To tell the truth, 'whimpering' was second only to the "training of dolts and blockheads" i.e. private tutoring). Once during the workshop's time at our Department I had to whimper. Boris Vladimirovich Gnedenko was very angry, as every other person in his place would have been. Vladimir Korolyuk protected me. In some time, I obtained results which were to the liking of B.V. Gnedenko, and so the misdeed was smoothed over.

During this time Vladimir Korolyuk actively took up social duties. He was the Head of the Trade Union of the Institute of Mathematics. He conducted staff meetings of the trade union bureau in a very business like way, and was intolerant towards verbosity. Vladimir Semenovich loved to have dinner at the restaurant "Cocktail Hall". Then the food was of very good quality, but in Kiev's restaurants you had to wait for an hour to be served with dinner. Vladimir Semenovich, at one time acted in the following way: he booked a dinner at the "Cocktail Hall", went to the Institute, conducted a staff meeting of the trade union bureau which lasted for forty minutes, and then came back to the restaurant exactly in time to eat his dinner.

Vladimir Semenovich reads a lot. He is interested in fiction, social and political journalism and many others. I think, he does not like long detailed descriptions, and so he tries to grab the main idea with a few sentences which he then considers to be a valuable find. I can still remember his witty explanation of "Parkinson's law".

Being a man of many interests and abilities, Vladimir Korolyuk always went in 
for tennis. At one time he was "ranked first" at the National Academy of Sciences in tennis.

Vladimir Korolyuk supported many mathematicians. In good time, such talented mathematicians as I.I. Ežov, B.B. Anisimov, and D.S. Silvestrov were supported by him a lot.

In Kiev, in the fifties and sixties, there were many scientific schools, groups and groupings. To put it mildly, all of them were unfriendly to each other. B.V. Gnedenko is a very kindhearted and responsive person, but he ended up in conflict with most of these groups, at least in the last period of his life in Kiev. His move to Moscow was not very peaceful. One of the people involved recalled in a private talk that, 'We trapped him in a cage with only one window as an exit. He had no way out except to go to Moscow'.

I can recollect how I was accepted to the position of Senior Research Fellow. I finished my postgraduate studies half a year ahead of schedule and obtained my $\mathrm{PhD}$ degree. The new director at The Institute of Mathematics Yu.A. Mitropolskii had a friendly attitude towards me from the very beginning, and Vladimir Korolyuk, himself wrote a character reference for me. (This old and tattered sheet of paper is still carefully kept by me now). The confirmation of my assignment took place at the Presidium of the Academy of Sciences.

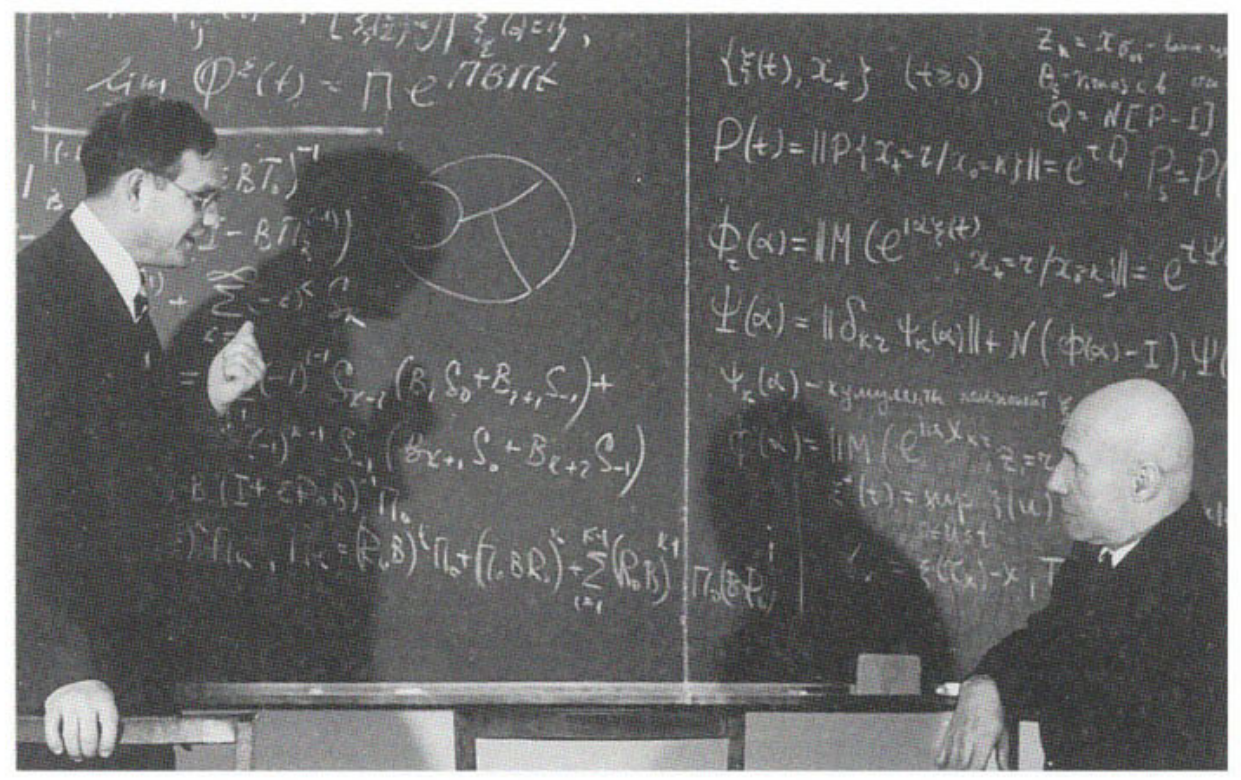




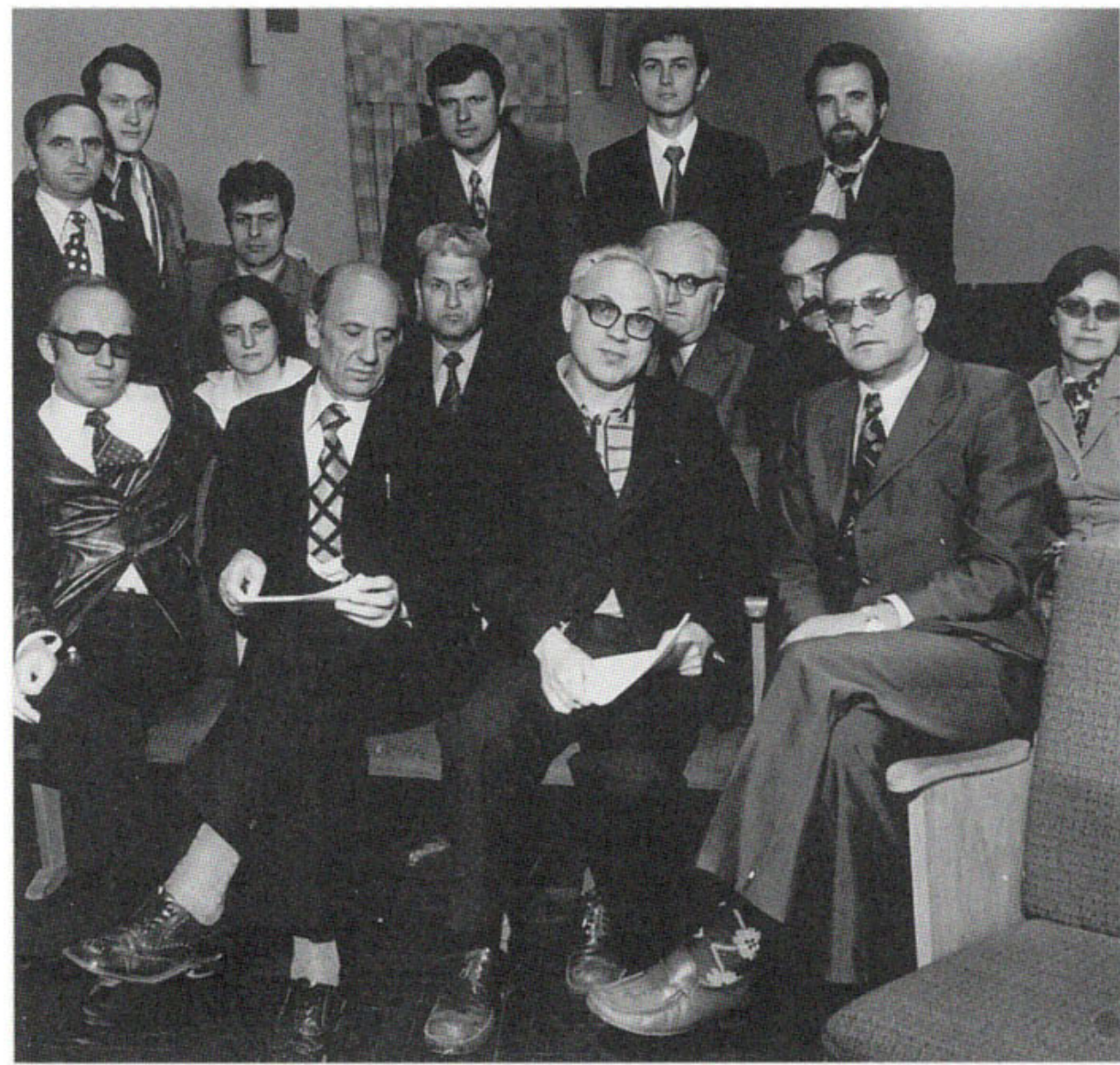

Leading specialists of Kiev Probability School

from right to left:

Front row - V.S. Korolyuk, A.V. Skorokhod, I.I. Gikhman, I.I. Ežov

2nd row - M.M. Diesperova, M.I.Portenko, M.I. Yadrenko, A.Ya. Dorogovtsev, G.N. Sytaya, D.V. Gusak

3rd row - A.F. Turbin, D.S. Selivestrov, A.A. Anisimov, R.V. Boiko, G.F. Butsan

One of the former Vice-Presidents of the Academy examined the candidates to this position. He mounted the Presidium chair and we were allowed to enter the hall in turn and stood near the door at a distance of 15 metres from him, and were then questioned:

'Who is your supervisor?'

'Academician Gnedenko.'

'Did he really supervise your work?'

'Yes, he did supervise it.'

'Ha-ha!' 
'And what is the subject of your dissertation?'

'It is ...'

'And what do you study there?'

'I generalize such results.'

'Well, then is the work compilation?' ...

This arch-academician did not understand what generalization means in mathematics; I could feel his unfriendly attitude towards B.V. Gnedenko.

I cannot remember one of Gnedenko's students becoming his adversary or behaving in an unfriendly way towards him. Vladimir Korolyuk was exemplary in this situation: he maintained both a deep respect for his teacher and for the traditions of the school. And on top of this Vladimir Korolyuk had a good relationship with his teacher's opponents. Generally, Korolyuk is distinguished by his ability to establish contacts with people, recognizing their best features. At the same time, I must emphasize that Vladimir Semenovich is a man of principle who believes in standing up for the truth, and will argue vehemently for it.

I described my impression of V.S. Korolyuk, relating to a short time interval, approximately from 1955 to 1962 . In my so-called permanent memory, pictures of scientific and human contacts with him at that time appear in my mind most distinctly, although 30 years have passed. Memories of him delivering a lecture in programming; of him supervising the newly introduced practical professional training of the fourth year students at the University and, together with us, shaking in the bus (which was said to have been used previously for a funeral) on the road to the Computing Center in Feofania. I have memories of him at the USSR Congress of Mathematicians in Moscow in 1956 (there were present some of us students, as representatives of The Students Scientific Society). I remember when we swam together with Kolmogorov and Michalevich in the Dnieper. I remember him at the USSR Conference in Erevan, Tbilisi, and Uzhgorod. (Famous mathematician Sir David Kendall from Cambridge has the photograph of the Tbilisi Conference, where in front of the auditorium there are Kolmogorov, Gnedenko and Korolyuk). I have memories of him with his "comrades in arms" I.I. Gikhman, A.V. Skorokhod, M.I. Yadrenko, and others. I remember Vladimir Semenovich in a cybernetic group with L.A. Kaluzhnin at the head. And I have many other pictures connected with this marvellous man treasured in my "permanent" memory.

To his good health, happiness and future success!

May 5, 1995

Igor N. Kovalenko 
